\title{
(C)]
}

\section{ANÁLISE ERGONÔMICA DE UM FERRO DE PASSAR SEM FIO DESENVOLVIDO COM ÊNFASE NO DESIGN EMOCIONAL}

\section{ERGONOMIC ANALYSIS OF A PASS WITHOUT IRON WIRE DEVELOPED WITH EMPHASIS ON EMOTIONAL DESIGN}

\author{
SILVA, Rachel de Oliveira Queiroz (1); \\ (1) Especialista, Instituto de Educação Superior da Paraíba \\ e-mail:kelqueiroz@gmail.com
}

\begin{abstract}
RESUMO
Esse artigo trata de parte de um projeto que teve como objetivo o desenvolvimento de um ferro de passar roupas sem fio com ênfase no design emocional. Esse relato tem o objetivo de apresentar a metodologia de análise ergonômica, bem como seus resultados. Por fim, é apontada uma relação entre os insumos da análise, as partes do produto e as tarefas em que estão relacionadas.
\end{abstract}

Palavras-chave: Ergonomia; Usabilidade; Ferro de Passar.

\section{ABSTRACT}

This article is part of a project that aimed to develop an iron wireless clothing with emphasis on emotional design. This report aims to present the ergonomic analysis methodology and its results . Finally, it is pointed out a relationship between the analysis of inputs, parts of the product and the tasks that are related.

Keywords: Ergonomics ; Usability ; Iron.

\section{INTRODUÇÃO}

O presente artigo trata da avaliação ergonômica de um projeto de um ferro de passar roupas sem fio, desenvolvido com ênfase no design emocional. E tendo como objetivo realizar o projeto de um produto nesse escopo foi realizado um levantamento bibliográfico e em seguida, uma análise dos insumos teóricos pesquisados e de produtos similares existentes no mercado.

No ambiente doméstico o ferro de passar é um utensílio indispensável. Apesar de existir diversos modelos, ainda persistem alguns problemas no ferro de passar roupa que demandam soluções de design. Entre os problemas, aqueles que são explorados mais diretamente neste projeto incluem:

1) Todos os ferros elétricos, com exceção dos que funcionam através de bateria, necessitam do fio para seu funcionamento. Em alguns aparelhos o fio torna-se um problema por ser 


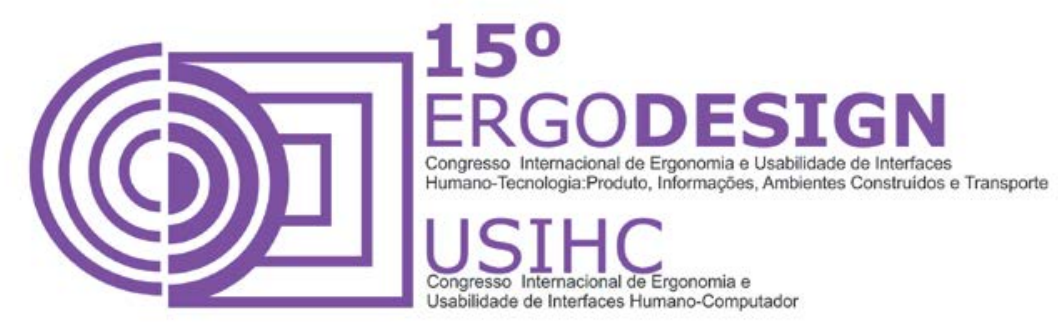

curto, impedindo assim sua utilização à longa distância. Além disso, um dos problemas mais comuns de um ferro elétrico refere-se à possibilidade do curto-circuito causado por maucontato no fio elétrico, podendo causar incêndio.

2) Outro problema comum é o de armazenagem. A grande maioria dos usuários dos ferros elétricos não possui um local adequado para o armazenamento do produto. Alguns usuários guardam o seu ferro elétrico em suportes de alumínio. Outros guardam em estantes ou nas próprias tábuas de passar. Existe também um case de plástico utilizado para esse fim, no entanto ocupa mais espaço. A maioria das pessoas enrola o fio em volta do ferro e os deixam no próprio chão podendo causar acidentes.

3) O ferro elétrico é um dos maiores consumidores de energia, no ambiente doméstico é responsável por um consumo mensal entre 10 e $15 \mathrm{kWh}$, cerca de $5 \%$ a $7 \%$ do consumo total de uma residência.

Pelo exposto acima, o projeto atende a demanda da interação do design através do desenvolvimento de um ferro de passar roupa que possa (1) resolver problemas identificado no armazenamento do fio; (2) otimização do espaço para armazenamento do aparelho; (3) possibilitar controle e redução do consumo de energia; (4) agregar valore estéticos, semânticos e emocionais a partir do design centrado no usuário.

Existem ferros elétricos de diversos tamanhos, cores e materiais. Entretanto, não identificouse no mercado um ferro de passar que una quatro fatores fundamentais: funcionalidade, estética, inovação tecnológica e formal e economia de energia elétrica. Por ser um ferro sem fio e com suporte, o produto desenvolvido neste projeto facilitará a vida do usuário pelo menos de duas maneiras: tanto quanto a sua usabilidade, quanto ao seu armazenamento. Sendo assim, o projeto propõe um produto diferenciado diante dos demais existentes no mercado.

O projeto também tem alcance social, pois visa à economia de energia elétrica, o que beneficia não apenas o indivíduo, mas toda a sociedade. Outro fator importante é a questão da segurança, pois o ferro, por ficar armazenado no próprio suporte, evita o contato e possíveis acidentes com crianças, animais ou mesmo adultos.

\section{ANÁLISE ESTRUTURAL E DE COMPONENTES}

Nesta etapa são analisadas as partes que compõem a estrutura de um ferro elétrico. Para realizar a análise foram escolhidos alguns ferros elétricos de diferentes marcas e modelos com o intuito de fazer uma comparação de suas partes. Os ferros escolhidos foram o Arno Forma 20, o Black and Decker F300 e o Britânia FB23 (Figura 1).

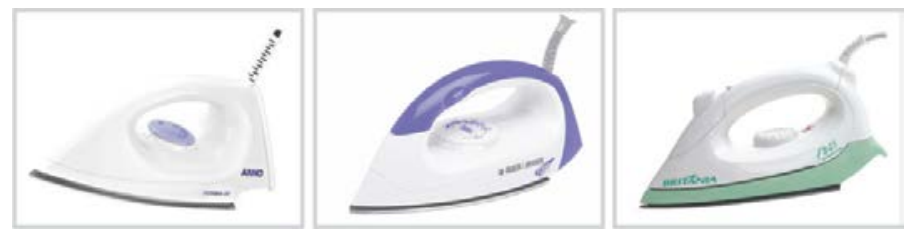

Figura 1: Ferros analisados estruturalmente 


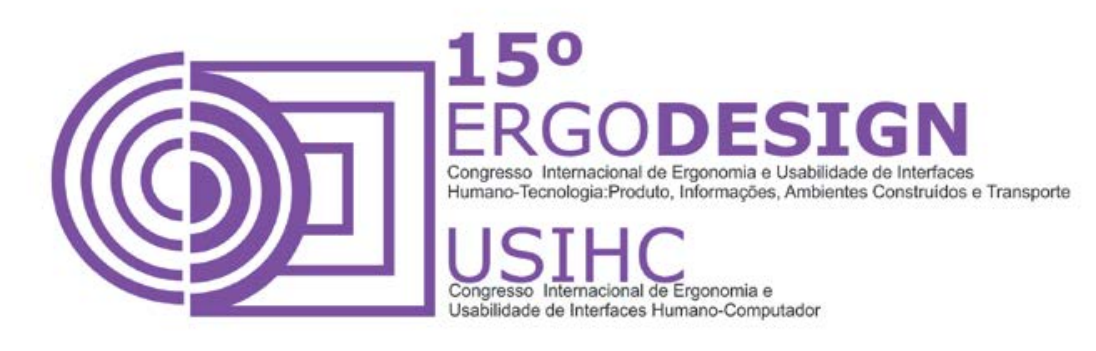

\subsection{Salva-Botões}

Os ferros elétricos possuem salva botões (Figura 2), que são aberturas entre a base metálica e o corpo do ferro. Em alguns ferros esta abertura é maior. Sua finalidade é facilitar a passagem do produto entre botões, costuras e cavidade das roupas.

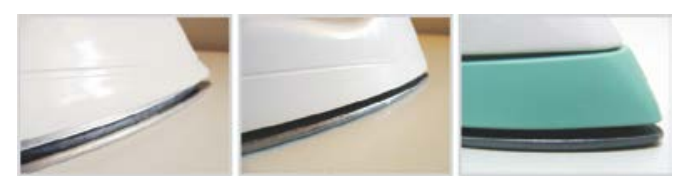

Figura 2: Salva-botões

\subsection{Face Frontal Pontiaguda}

Os ferros apresentam suas partes frontais pontiagudas (Figura 3) para possibilitar a tarefa de passar roupa e para penetrar entre um botão e outro. Estas bases são fixadas no corpo do ferro.

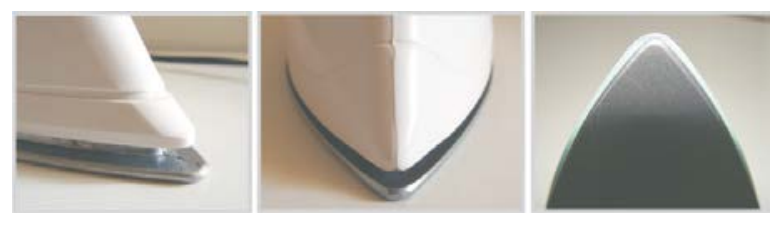

Figura 3: Bases dos ferros

\subsection{Baixo-Relevo}

Detalhes em baixo relevo (Figura 4), fazem parte da estrutura dos ferros, podendo ser 0 encaixe das partes dos produtos. Estes detalhes podem acumular sujeira.
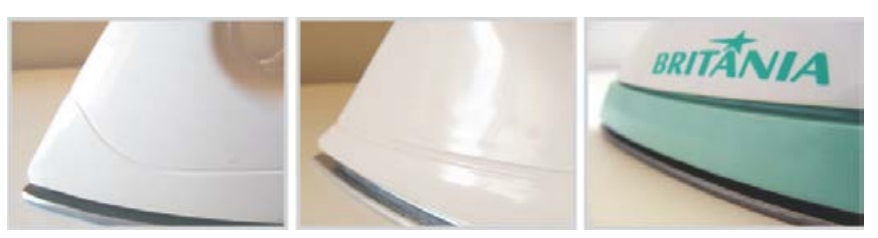

Figura 4: Baixo-relevo no corpo dos ferros

\subsection{Seletor de Temperatura}

Os ferros possuem os seletores de temperatura (termostato) giratório e circular (figura 5), localizados abaixo da pega. Em geral podem apresentar orifícios em baixo relevo ou ranhuras em alto relevo, proporcionando apoio para os dedos. Os termostatos são fixos por encaixe no corpo do ferro.



Figura 5: Seletor de temperatura 




\subsection{Demarcadores de Temperatura}

Ao lado do seletor de temperatura existe o demarcador de temperatura (Figura 6), podendo ser um alto relevo do próprio material do corpo ou ser a própria luz piloto.

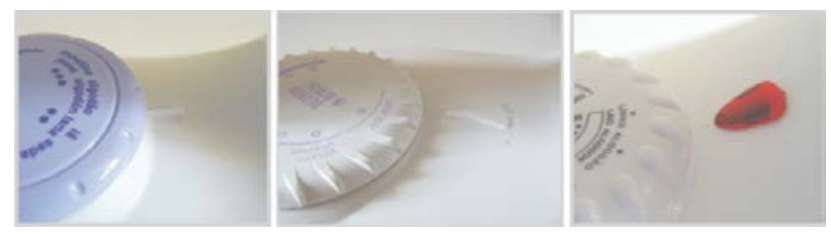

Figura 6: Demarcador dos tipos de tecidos

\subsection{Pegas}

As pegas são cilíndricas (figura 7), podem apresentar orifícios em baixo relevo que ajudam no apoio da mão do usuário, saliências, que funcionam como índice para o encaixe do dedo polegar ou podem ser lisos.

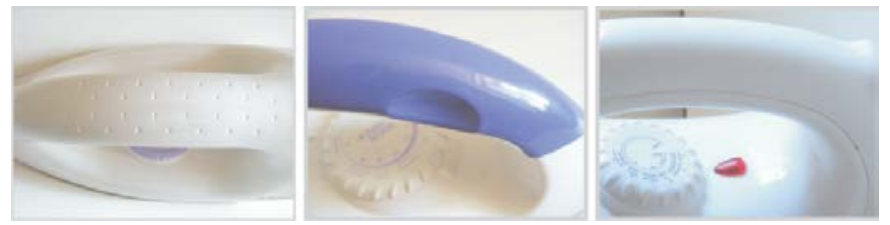

Figura 7: Pegas dos ferros

\subsection{Os Fios}

Os fios (figura 8) se localizam na parte posterior do produto e são centralizados, podendo apresentar-se bi-lateral ou com modalidade de $360^{\circ}$.

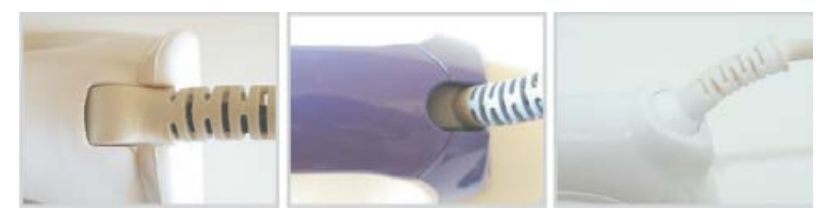

Figura 8: Sistema dos fios

\subsection{Parte Posterior}

A parte posterior (figura 9) apresenta uma forma triangular e um orifício, no qual está inserido um parafuso de fixação.

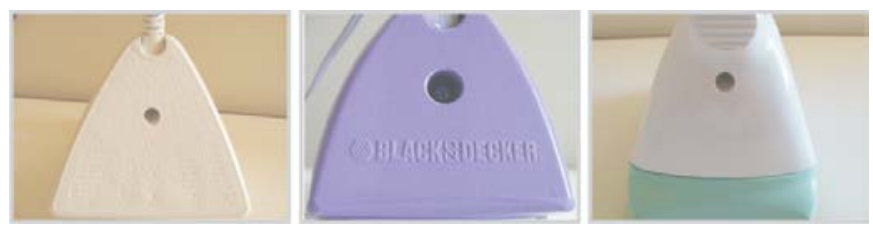

Figura 9: Parte posterior dos ferros

\subsection{Principais Medidas do produto}




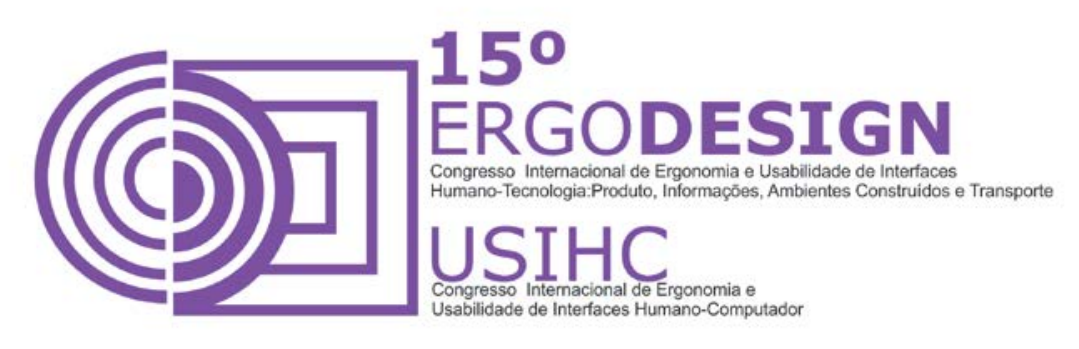

As dimensões principais dos ferros (Altura $x$ Largura) variam entre $12,5 \times 25,9 \mathrm{~cm}$ e 11,5 $x 23,5 \mathrm{~cm}$ (figuras 10). A largura apresenta uma variação entre $24,2 \mathrm{~cm}$ e $25,5 \mathrm{~cm}$. A altura varia entre $12,0 \mathrm{~cm}$ e $13,0 \mathrm{~cm}$. O comprimento varia entre 11,0 e 13,0 cm (Figura 34)
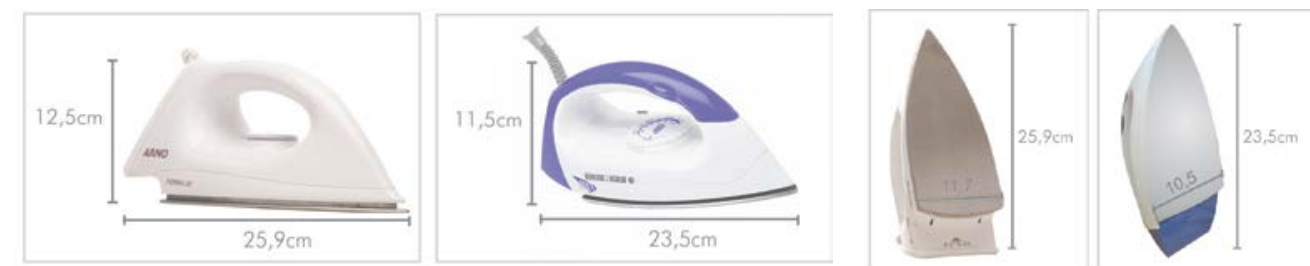

Figura 10: Principais dimensões

\section{ANÁLISE ERGONÔMICA E DE USABILIDADE}

A partir das medidas analisadas anteriormente pôde-se observar que alguns ferros são mais compactos que os outros, sendo estes de maior facilidade de uso e manuseio, exercendo a tarefa tão bem quanto os outros que são maiores.

O termostato (seletor de temperatura) que em geral se localiza abaixo da pega (figura 11), apresenta diâmetro entre $5 \mathrm{~cm}$ e $5,50 \mathrm{~cm}$, adequados ao tamanho da mão dos usuários (homem e mulher). Entretanto há um pouco de dificuldade com relação à localização, pois está logo abaixo do cabo do ferro, dificultando a visibilidade dos tipos de tecidos. Além disso, o tamanho dos nomes, que em geral são pequenos, dificultando a leitura.


Figura 11: Medida e usabilidade do termostato

A forma da pega dos ferros tem forma anatômica, cilíndrica, encaixam bem na mão do usuário, seja ele homem ou mulher. Com relação ao seu diâmetro, a pega varia entre $3,0 \mathrm{~cm}$ e $3,5 \mathrm{~cm}$, o que está dentro do limite máximo das medidas antropométricas, que é varia entre 3,17 e $3,81 \mathrm{~cm}$ (figura 12). 


\section{((1))}


Figura 12: Indicação-Limite das medidas antropométricas para o cilindro e espaçamento da pega

As dimensões da parte interior da pega, parte entre a pega e o termostato (figura 13), varia entre 2,50 e $3,0 \mathrm{~cm}$ de altura e entre 9,50 e $12,0 \mathrm{~cm}$ de comprimento. Ambos apresentam um espaço adequado para que a mão do usuário (homem e mulher) fique encaixada de maneira confortável e segura.

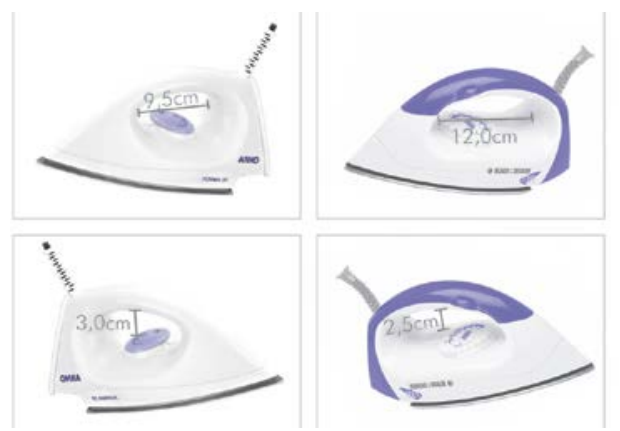

Figura 13: Espaço entre o termostato e a pega

A parte posterior do ferro (figura 14) apresenta forma triangular, com linhas retilíneas que apresentam uma medida que varia entre 7,0 e $11,0 \mathrm{~cm}$ de base. Já o segundo apresenta a base do triangulo com $7,0 \mathrm{~cm}$. O primeiro por ter área de contato maior com a superfície, fica apoiado na vertical com maior segurança. O segundo por ter uma área de contato menor tem menos estabilidade.

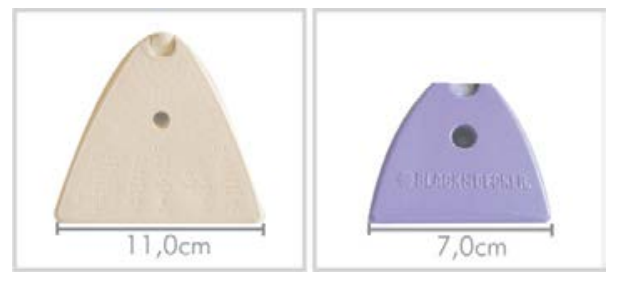




\section{(C) 1 (D)}

Figura 14: Medida da parte posterior do ferro

A base dos ferros também se apresenta com um formato triangular. A ponta superior do triângulo é de grande utilidade no momento em que se passam algumas partes das roupas, como por exemplo, entre os botões. A ponta do ferro se encaixa bem entre um botão e o outro, possibilitando uma melhor usabilidade do produto e um melhor resultado final da roupa (figura 15).



Figura 15: Parte pontiaguda da base do ferro

\subsection{Análise Quanto ao Uso: Funcional}

O usuário do ferro se enquadra nos homens do percentil 50 (TILLEY, 2005) e foi um dos participantes da pesquisa de campo.

$1^{\circ}$ Passo: Encaixe do plugue do ferro na tomada.

Nesta imagem pode-se observar que o usuário se abaixou para desempenhar a tarefa, para isso a tábua de passar precisa estar próxima a tomada, para que o fio chegue até ela, sendo esta uma das maiores reclamações dos usuários de ferros elétrico com fio. Análise dos Dados

\section{$2^{\circ}$ Passo: Selecionar o tipo de tecido no termostato}

Nesta imagem pode-se observar que o usuário segura o ferro com uma mão e com a outra escolhe o tipo de tecido. Observa-se também que o espaço entre o termostato e o cabo do ferro é um pouco pequeno para o encaixe dos dedos do usuário.

$3^{\circ}$ passo: Passar a roupa

Pode-se observar que nesta imagem o usuário segura o ferro com uma mão enquanto ajeita a roupa com a outra e assim desliza o ferro sobre o tecido. Nesta etapa o maior número de reclamações foi quanto ao fio. De acordo com os participantes da pesquisa eles dizem que o fio engancha na tábua de passar, ou fica na frente da roupa.

$4^{\circ}$ passo: Apoiar o ferro na vertical

Nesta imagem pode-se observar que o usuário apoia o ferro na vertical. Nesta tarefa é preciso que o ferro tenha uma base firme, para que possa ficar na vertical com segurança.

$5^{\circ}$ passo: Desligar no seletor de temperatura

Após o término da tarefa de passar, o usuário desliga o ferro escolhendo a opção desligar no seletor de temperatura. Esta fase apresenta os mesmo problemas do $2^{\circ}$ passo. 


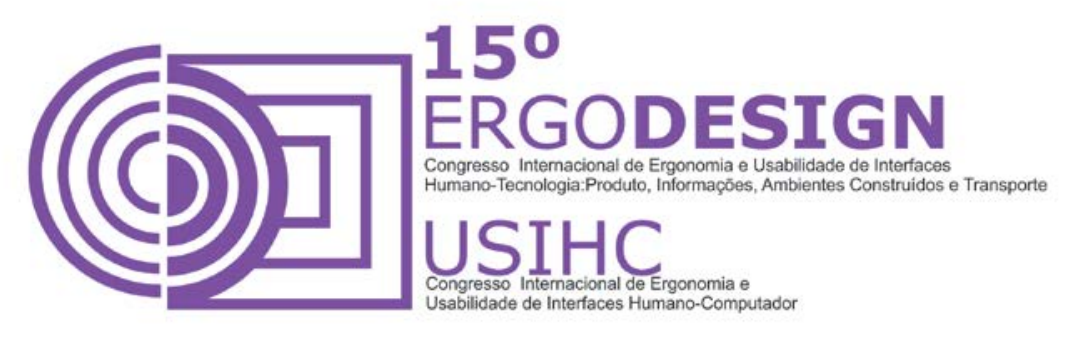

$6^{\circ}$ passo: Apoia o ferro na lateral da tabua de passar

A imagem mostra o usuário apoiando o ferro sobre o suporte da tabua de passar para que o ferro esfrie, e depois ser armazenado em outro lugar. Um dos problemas que podem ser ocasionados por esta tarefa é a possibilidade de causar acidentes, pois o ferro ainda estará quente e exposto sem nenhuma segurança. Na aplicação dos questionários, pôde-se observar que o armazenamento dos ferros é um grande problema para os usuários, pois muitos não apresentam um local adequado para este fim. Muitas vezes o ferro é guardado sobre o chão, em armários, guarda roupa ou suporte da tábua de passar.

$7^{\circ}$ passo: retirar o plugue do ferro da tomada

Nesta imagem pode-se observar que o usuário se agacha para retirar o plugue do ferro da tomada. Repetindo o $1^{\circ}$ passo, com a diferença que nesta etapa o ferro não se encontra na mão do usuário e sim no suporte da tábua de passar.

$8^{\circ}$ passo: enrolar o fio ao redor do ferro

Nesta imagem pode-se observar que o usuário segura o ferro com uma mão e enrola o fio ao redor dele com a outra. Esta tarefa é executada após o ferro estar frio. A maneira de enrolar o fio demonstrada na imagem é comum e errada, pois pode causar curto circuito, com possibilidade de incêndio.

\section{ANÁLISE ERGONÔMICA DO FERRO DE PASSAR PROJETADO}

\subsection{Pega}

As dimensões da pega foram analisadas a partir da indicação-limite das medidas antropométricas para o cilindro e espaçamento da pega (figura 00). Assim a pega apresenta uma largura de $3,20 \times 2,5 \mathrm{~cm}$ (LXA) e o vazado da pega mede 10,0x3,5cm (LXA), (figura 16).


Figura 16: Medidas da pega do ferro

\subsection{Salva Botões}

No ferro desenvolvido, o salva botões apresenta uma ponta pontuda e ao mesmo tempo arredondada que facilita a tarefa entre botões, bolsos e outras partes das roupas (figura 17). 




Figura 17: Salva-botões

\section{DESCRIÇÃO DE USO}

\subsection{Tarefa de passar}

A tarefa de passar roupa inclui as seguintes tarefas:

- Desencaixe o ferro e o suporte da base fixa ou se o usuário passar a roupa próximo à parede onde o ferro está fixado:

- Abre a tampa do suporte (figura 18).
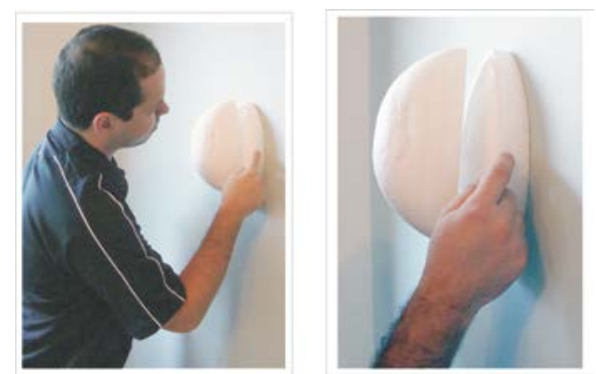

Figura 18: Usuário abrindo a tampa do suporte

- Conecta o plugue do suporte na tomada.

- Escolhe o tipo de tecido no seletor de temperatura (figura 19).
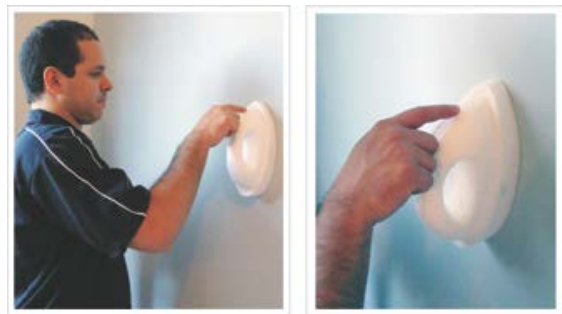

Figura 19: Usuário selecionando a temperatura

- retira o ferro do suporte (figura 20). quando a luz piloto acende

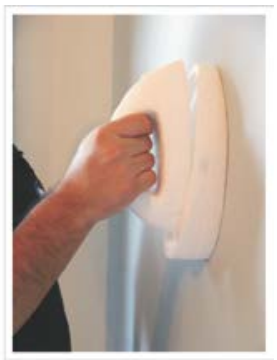




\section{((1))}

Figura 20: Usuário desencaixando o ferro do suporte

- Passa a roupa (figura 21).
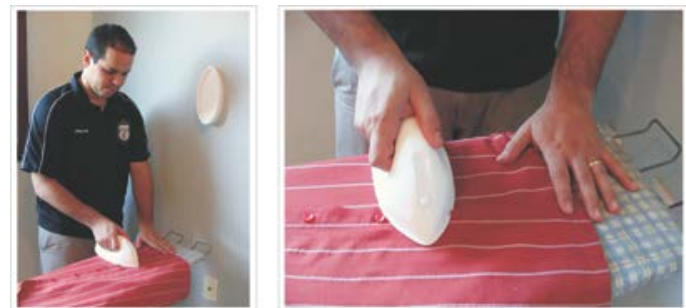

Figura 21: Usuário passando a roupa

\subsection{Tarefa de Armazenar o produto:}

Ao finalizar a tarefa de passar roupa, o armazenamento do produto inclui:

- Desligar o plugue da tomada.

- Encaixar o ferro no suporte (figura 22).



Figura 22: Usuário encaixando o ferro no suporte

- Apertar o botão para que o fio volte para o interior do suporte, e encaixe do plugue no suporte (Figura 23).

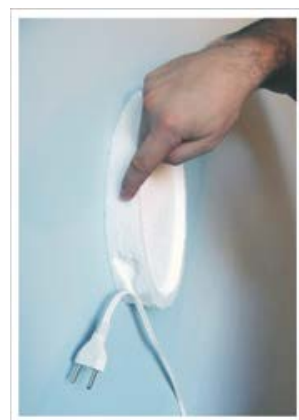

Figura 23: Usuário apertando o botão para o fio retornar ao suporte 


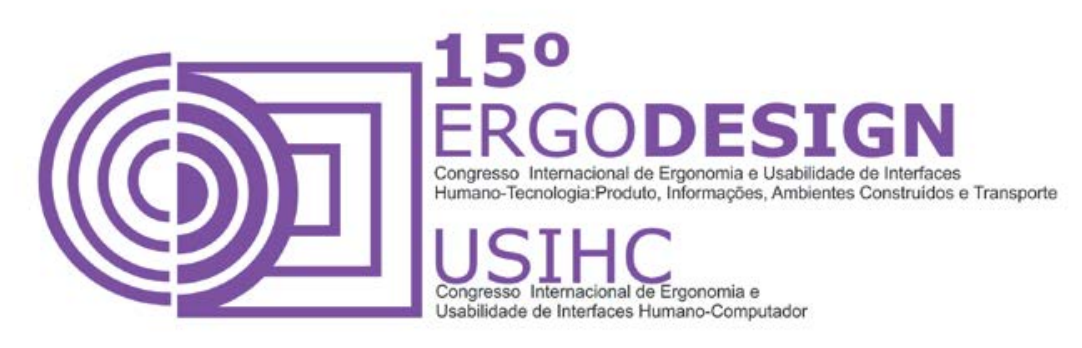

- Fechar a tampa do suporte (Figura 24).

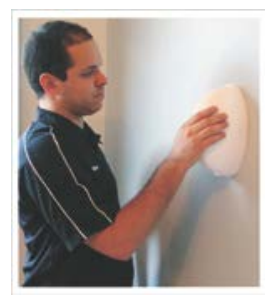

Figura 24: Usuário fechando a tampa

\section{REFERÊNCIAS BIBLIOGRÁFICAS}

ARNO. Ferros para Cuidados com Suas Roupas. Disponível em: <http://www.arno.com.br/ produtos/cuidados-suas-roupas/ferros/12/>. Acesso em: 12 de fev. de 2009.

BAXTER, Mike. Projeto de produto: guia prático para o design de novos produtos. 2.ed. Tradução: Itiro lida. São Paulo: Edgard Blücher, 2001.

BLACKANDDECKER. Roupa e Limpeza. Disponível em: <http://www.blackanddecker.com.br/ bdprod/cata/grupo.asp?idGrup=ROUP>. Acesso em: 12 de fev. de 2009.

BOMFIM, Gustavo A. Metodologia para desenvolvimento de projetos. João Pessoa: Editora Universitária/UFPB, 1995.

BOTTON, Alain de. A arquitetura da Felicidade. Rio de Janeiro: Ed. Rocco, 2007.

CORREIA, Walter F. Marques ; SOARES, Marcelo M. Usabilidade e acidentes em produtos de consumo: um estudo na cidade de Recife, PE. Universidade Federal de Pernambuco, 2003.

DAMÁSIO, António R. O Erro de Descartes: Emoção, Razão e o Cérebro Humano. Companhia das Letras, São Paulo, 1996.

DAMAZIO, Vera. Artefatos de Memória da Vida Cotidiana - um Olhar sobre as Coisas que Fazem Bem Lembrar, Universidade do Estado do Rio de Janeiro, 2006.

DAMAZIO, Vera. Algumas considerações sobre a relação emocional entre as pessoas e o entorno projetado. Departamento de Artes, PUC - Rio. 2006.

DE MORAES, Anamaria. Ergonomia e Usabilidade - parâmetros fundamentais para garantir a segurança e o conforto dos usuários. Laboratório de Ergonomia e Usabilidade de Interfaces em Sis-temas Humano -Tecnologia - UFRJ, 2006.

GOMES FILHO, João. Design do Objeto: Bases Conceituais. Editora. Escrituras, São Paulo, 2006.

GOMES FILHO, João. Ergonomia do Objeto: Sistema Técnico de Leitura Ergonômica. Editora Escrituras, São Paulo, 2007.

HANCOCK, P.; PEPE, A.; MURPHY, L. Hedonomics: The power of positive and Pleasurable Ergonomics. In: Ergonomics in Design. Winter, v. 13, n. 1, p. 8-14, 2005. 


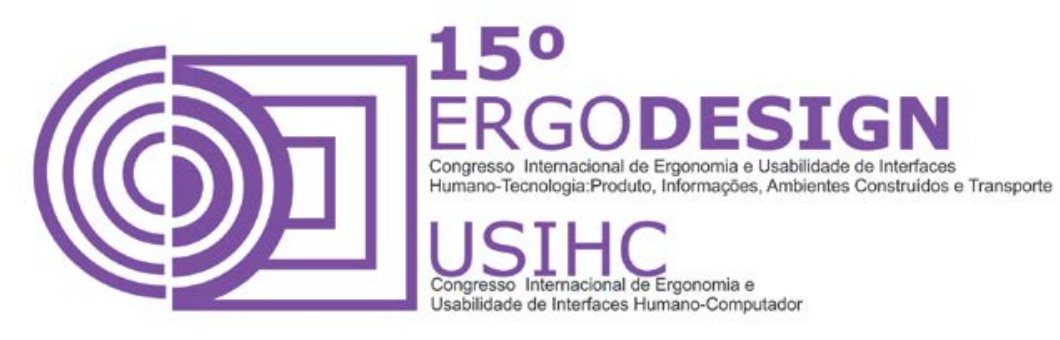

IIDA, Itiro. Ergonomia, Projeto e Produção. São Paulo: Editora: Edgard Blücher Ltda, 1998. IIDA, Itiro; MÜHLENBERG, Poema. O Bom e o Bonito em Design. Universidade de Brasília, 2006.

INMETRO. Ferro Elétrico de Passar Roupa. Disponível em: <http://www.inmetro.gov.br/ consumidor/produtos/ferroeletrico.asp>. Acesso em: 15 de mar. de 2009.

JORDAN, Patrick W. Entrevista com Patrick W. Jordan, URL: <http://www.designemotion.com /2006/12/04/getting-emotional-with-pat-jordan/>. Acesso em: 15 de mar. de 2009.

LIMA, Marco A. M. Introdução aos Materiais e Processos para Designers. Rio de Janeiro: Editora Ciência Moderna LTDA, 2006.

LÖBACH, Bernd. Design industrial: bases para a configuração dos produtos industriais. São Paulo, Edgard Blucher, 2001.

MEDEIROS, Wellington Gomes de. Apostila Introdução à Teoria da Informação e à Semiótica. Universidade Federal de Campina Grande, Unidade Acadêmica de Desenho Industrial, 2002.

MEDEIROS, Wellington Gomes de. Dimensões denotativa e conotativa da forma em embalagens estruturais, 3rd Design Research International Conference, Rio de Janeiro, 2005.

MEDEIROS, Wellington Gomes de. Interação Significante (IS): Dimensão Semântica da Interação de Usuários com Produtos. $7^{\circ}$ Congresso de Pesquisa e Desenvolvimento em Design - Paraná, 2006.

MEYER, Guilherme C.; MATTEDI, Marcos A. Sociedade e Objeto, as Influências de um sobre o outro. $7^{\circ}$ Congresso de Pesquisa e Desenvolvimento em Design - Paraná, 2006.

MONT'ALVÃO, Claudia; DAMAZIO, Vera (Orgs.). Design, ergonomia e emoção. Rio de janeiro: Mauad X e FAPERJ, 2008.

NIEMEYER, Lucy. Elementos de Semiótica Aplicados ao Design, Rio de Janeiro: 2AB Série Design, 2003.

NORMAN, Donald A. Design Emocional: por que adoramos (ou detestamos) os objetos do dia-a-dia. Tradução de Ana Deiró. Rio de Janeiro: Rocco, 2008. Título original: Emotional Design - Why We Love (or Hate) Everyday Things.

PHILIPS WALITA. Ferro de passar roupa. Disponível em: <http://www.consumer.philips.com/ consumer/pt/br/walita/ce/p/consumer/consumer_landing_page $>$. Acesso em: 12 de fev. de 2009.

TILLEY, Alvin R. As Medidas do Homem e da Mulher - Fatores humanos em design. Henry Dreyfuss Associates. Tradução: Alexandre Salvaterra. Porto Alegre: Bookman, 2005.

VELLOSO, Verônica P. A eletricidade no Brasil sob a perspectiva da história social. Departamento de Pesquisa da Casa de Oswaldo Cruz - Fiocruz, 2002. 